\title{
Assessment of biological and molecular variability between and within field isolates of Plasmodiophora brassicae
}

\author{
M. J. Manzanares-Dauleux ${ }^{\star} \dagger$, I. Divaret, F. Baron and G. Thomas \\ INRA Station d'Amélioration des Plantes, BP 35327, 35653 Le Rheu Cedex, France
}

\begin{abstract}
Plasmodiophora brassicae is an obligate biotroph that causes clubroot, one of the most damaging diseases of crucifers. Differential cultivars and random amplified polymorphic DNA markers were used to assess the extent of genetic diversity among nine single-gall populations of P. brassicae and 37 single-spore isolates (SSI) derived from four of those field samples. Isolates were classified into eight pathotypes, and each isolate was associated with a unique molecular genotype. Virulence and DNA polymorphisms were detected within and between field isolates, and among SSIs from different pathotypes, hosts and geographical origins. The relatively high level of genetic diversity among field isolates was similar to that among SSIs derived from a single-club field isolate. Molecular and pathogenicity-based classifications were not clearly correlated, but isolates belonging to pathotype P1 were clustered. Two RAPD markers were specific to pathotype P1. The finding that genetic differences can occur in P. brassicae field isolates will be an important consideration in resistance genetic studies and in choosing breeding strategies to develop durable clubroot resistance.
\end{abstract}

Keywords: clubroot, crucifers, molecular markers, RAPD, single-spore isolates, virulence

\section{Introduction}

Plasmodiophora brassicae is a soilborne, obligate biotroph that causes clubroot, one of the most damaging diseases of crucifers. The life cycle of the parasite consists of two main phases, the first occurring in root hairs, the second in cells of the root cortex and stele leading to gall formation and production of haploid resting spores. The clubs formed inhibit nutrient and water transport, stunt the growth of the plant and increase susceptibility to wilting. Plasmodiophora brassicae occurs worldwide and has an extensive host range, which includes the cultivated Brassica species and wild crucifers such as Arabidopsis thaliana (Koch etal., 1991). Cultural practices and/or chemical treatments have been unsuccessful in protecting crops or have proved too expensive. Therefore the development of resistant cultivars is now considered the most economical and efficient method for the control of clubroot.

Successful breeding and effective deployment of durable plant resistance require an understanding of pathogen diversity and of the way in which virulence evolves in pathogen populations. Very little is known about the extent and mechanisms of variability in $P$. brassicae. Significant differences in pathogenicity

*To whom correspondence should be addressed.

†E-mail: manzanar@rennes.inra.fr

Accepted 9 October 2000. have been recognized among field populations of $P$. brassicae using sets of differential hosts (Williams, 1966; Buczacki et al., 1975; Crute et al., 1980; Voorrips, 1995; Somé et al., 1996; Kuginuki et al., 1999). Variation in virulence was also demonstrated within field isolates (i.e. P. brassicae isolated from a single root gall) by using single-spore isolates (Haji Tinggal \& Webster, 1981; Jones et al., 1982a; Scott, 1985; Schoeller \& Grunewaldt, 1986; Somé et al., 1996). Few alternative molecular methods have been developed to define further the extent of genetic variation within pathogen populations. Polymerase chain reaction (PCR) primers derived from putative repetitive/ high-copy-number DNA sequences of $P$. brassicae have been described by Buhariwalla et al. (1995) as potential markers of genetic variation. Möller \& Harling (1996) used RAPD markers to differentiate three isolates of $P$. brassicae. However, the structure of pathogenic variability has received little attention in $P$. brassicae. To date, no studies have been reported concerning genetic variation within and between field isolates and between different single-spore isolates.

The objectives of the current research were (i) to study the genetic variability within and between $P$. brassicae field isolates in terms of virulence and DNA polymorphism; (ii) to detect genomic polymorphism directly related to pathotype classification; and (iii) to identify molecular markers that can be used for tracking specific isolates of the pathogen. 


\section{Materials and methods}

\section{Plasmodiophora brassicae isolates}

Forty-six isolates, nine field isolates and 37 single-spore isolates (SSIs) of P. brassicae were studied (Table 1). Field isolates were collected from single galls of naturally infected cauliflower (Brassica oleracea conv. botrytis), rapeseed (B. napus var. oleifera) and Chinese cabbage (B. rapa spp. pekinensis, cv. Granaat) grown in Brittany (north-western France), either in different fields or in the same field but sampled over several years. Single-spore isolates were obtained from four of these field isolates ( $\mathrm{PbM}$, K92, SJ92 and $\mathrm{Pb} 137$; Table 1) as

Table 1 Characteristics and pathotype designation as determined in this study of 46 field and single-spore isolates (SSI) of Plasmodiophora brassicae

\begin{tabular}{|c|c|c|c|c|c|c|}
\hline $\begin{array}{l}\text { Type of } \\
\text { isolate }\end{array}$ & $\begin{array}{l}\text { Source field isolate }{ }^{a} \\
\text { (pathotype) }\end{array}$ & Host & $\begin{array}{l}\text { French } \\
\text { district }\end{array}$ & $\begin{array}{l}\text { Year of } \\
\text { collection }\end{array}$ & Isolate & Pathotype $^{b}$ \\
\hline \multirow[t]{9}{*}{ Field } & & Rapeseed & Côtes d'Armor & 1993 & $\mathrm{PbM}$ & P1 \\
\hline & & Cauliflower & Finistère & 1991 & $\mathrm{~Pb} 137$ & P5 \\
\hline & & & Ille-et-Vilaine & 1992 & K92 & P2 \\
\hline & & & & 1992 & SJ92 & P5 \\
\hline & & & & 1993 & SJ93 & P1 \\
\hline & & Chinese cabbage & Finistère & 1993 & K93 & P1 \\
\hline & & & & 1994 & K94 & P7 \\
\hline & & & & 1995 & K95 & P7 \\
\hline & & & & 1996 & K96 & P7 \\
\hline \multirow[t]{37}{*}{$\mathrm{SSI}^{\mathrm{C}}$} & $\mathrm{PbM}(\mathrm{P} 1)$ & Rapeseed & Côtes d'Armor & 1993 & Ms6 & P1 \\
\hline & & & & & M651 & P1 \\
\hline & & & & & M727 & P1 \\
\hline & & & & & M746 & P1 \\
\hline & & & & & M774 & $\mathrm{P} 1$ \\
\hline & K92 (P2) & Cauliflower & Finistère & 1992 & K92-42 & P1 \\
\hline & & & & & K92-33 & P3 \\
\hline & & & & & K92-18 & P3 \\
\hline & & & & & K92-16 & P4 \\
\hline & & & & & K92-19 & P4 \\
\hline & & & & & K92-118 & P4 \\
\hline & & & & & K92-8 & P6 \\
\hline & & & & & K92-24 & P7 \\
\hline & & & & & K92-32 & P7 \\
\hline & Pb137 (P5) & Cauliflower & Finistère & 1991 & $\mathrm{~Pb} 137-436$ & P4 \\
\hline & & & & & $\mathrm{Pb} 137-437$ & P4 \\
\hline & & & & & $\mathrm{Pb} 137-514$ & P4 \\
\hline & & & & & $\mathrm{Pb} 137-538$ & P4 \\
\hline & & & & & $\mathrm{Pb} 137-560$ & P4 \\
\hline & & & & & $\mathrm{Pb} 137-524$ & P5 \\
\hline & & & & & $\mathrm{Pb} 137-418$ & P7 \\
\hline & & & & & $\mathrm{Pb} 137-434$ & P7 \\
\hline & & & & & $\mathrm{Pb} 137-439$ & P7 \\
\hline & & & & & Pb137-499 & P7 \\
\hline & & & & & $\mathrm{Pb} 137-522$ & $\mathrm{P} 7$ \\
\hline & & & & & $\mathrm{Pb} 137-532$ & $\mathrm{P} 7$ \\
\hline & & & & & $\mathrm{Pb} 137-543$ & $\mathrm{P} 7$ \\
\hline & & & & & Pb137-555 & $\mathrm{P} 7$ \\
\hline & & & & & Pb137-566 & $\mathrm{P} 7$ \\
\hline & & & & & $\mathrm{Pb} 137-574$ & $\mathrm{P} 7$ \\
\hline & & & & & $\mathrm{Pb} 137-576$ & $\mathrm{P} 7$ \\
\hline & & & & & $\mathrm{Pb} 137-483$ & P8 \\
\hline & SJ92 (P5) & Cauliflower & Ille-et-Vilaine & 1992 & SJ92-225 & $\mathrm{P} 1$ \\
\hline & & & & & SJ92-336 & P1 \\
\hline & & & & & SJ92-256 & P4 \\
\hline & & & & & SJ92-233 & P5 \\
\hline & & & & & SJ92-370 & $\mathrm{P} 7$ \\
\hline
\end{tabular}

${ }^{\text {a } F i e l d ~ i s o l a t e ~ f r o m ~ w h i c h ~ s i n g l e-s p o r e ~ i s o l a t e s ~(S S I s) ~ w e r e ~ d e r i v e d . ~}$

${ }^{\text {b}}$ Pathotype classification according to the disease reaction of three differential $B$. napus cultivars to the $P$. brassicae isolates (Somé et al., 1996). ${ }^{\mathrm{c}}$ For the SSIs, host of origin and year of sampling are those of the original field isolate. 
described previously (Manzanares et al., 1994; Somé et al., 1996). All the isolates were propagated on Chinese cabbage cv. Granaat. Clubs were washed and stored at $-20^{\circ} \mathrm{C}$ until required.

\section{Determination of $P$. brassicae pathotypes}

Classification of the isolates was performed according to the disease reaction of three differential B. napus cultivars as described previously (Somé et al., 1996). Designation of the pathotypes using this set is shown in Table 2. Each host/isolate combination was tested in a randomized complete block design with two replicates and 20 plants per replicate. Eight weeks after inoculation, plants were rated for disease reaction using the Buczacki et al. (1975) scale with one supplementary measure $(2+)$ : 0 , no visible swelling; 1 , very slight swelling usually confined to lateral roots; 2 , moderate swelling on lateral roots and taproot; $2+$, severe clubs on all roots but some roots remain; 3 , no root left, only one large gall. A disease index was calculated by summation of the coefficients $(0,25,50,75,100)$ affecting each plant class frequency (Buczacki et al., 1975). A cut-off point of $25 \%$ was used to classify reactions as virulent or avirulent. The tests were repeated at least twice to confirm the consistency of the virulence patterns.

\section{DNA isolation}

Genomic DNA of $P$. brassicae was extracted from resting spores. The spores were washed five times in sterile distilled water, dispersed in $100 \mathrm{~mm} \mathrm{MgCl}_{2}$, $200 \mathrm{~mm}$ Tris $\mathrm{pH} 7.4$ buffer and treated with DNase I $\left(30 \mu \mathrm{g} \mathrm{mL}^{-1}\right)$ for $3 \mathrm{~h}$ at $37^{\circ} \mathrm{C}$ to eliminate host DNA. The solution was centrifuged at $2500 \mathrm{~g}$ for $5 \mathrm{~min}$, and the pellet was recovered in $5 \mathrm{~mm}$ EDTA, $0.5 \%$ SDS, $10 \mathrm{~mm}$ Tris $\mathrm{pH} 7 \cdot 8$ buffer containing $20 \mu \mathrm{g} \mathrm{mL}^{-1}$ proteinase $\mathrm{K}$ for $30 \mathrm{~min}$ at $37^{\circ} \mathrm{C}$. After repeated centrifugations the final pellet was frozen in liquid nitrogen and lyophilized. DNA was extracted from lyophilized resting spores using a modified CTAB protocol (Doyle \& Doyle, 1990). Subsequently, DNA was also extracted using the same CTAB protocol from young leaves of plant host Chinese cabbage cv. Granaat. Dried spores or frozen leaves were ground in liquid nitrogen to a fine powder, dispersed in $25 \mathrm{~mL}$ hot CTAB extraction buffer, and incubated at $65^{\circ} \mathrm{C}$ for $30 \mathrm{~min}$. An equal volume of chloroform : octanol $(24: 1$, v/v) was added, and after agitation, the mixture was centrifuged at $3000 \mathrm{~g}$ for $45 \mathrm{~min}$. The upper aqueous phase was transferred to a further tube containing $16 \mathrm{~mL}$ isopropanol, incubated for $1 \mathrm{~h}$ at $4^{\circ} \mathrm{C}$ and centrifuged at $3000 \mathrm{~g}$ for $10 \mathrm{~min}$. The pellet was dissolved in $10 \mathrm{~mL}$ $1 \times \mathrm{TE}$ buffer containing $0.5 \mu \mathrm{g} \mathrm{mL}^{-1}$ RNAse, and incubated for $1 \mathrm{~h}$ at $37^{\circ} \mathrm{C}$. Samples were extracted with an equal volume of chloroform : octanol (24:1, v/v), and centrifuged at $3500 \mathrm{~g}$ for $10 \mathrm{~min}$. The DNA was precipitated with $0.5 \mathrm{vol} \mathrm{NaCl} 5 \mathrm{M}$ and $3 \mathrm{vol}$ cold
$100 \%$ ethanol. After $30 \mathrm{~min}$ incubation at $4^{\circ} \mathrm{C}$ the mixture was centrifuged at $3800 \mathrm{~g}$ for $10 \mathrm{~min}$, and the pellet rinsed with $70 \%$ ethanol. The DNA was dissolved in $100 \mu \mathrm{L} \mathrm{TE}$ buffer and stored at $-20^{\circ} \mathrm{C}$ until use.

\section{DNA amplification}

Approximately $12.5 \mathrm{ng}$ genomic DNA template was used in a $12.5 \mu \mathrm{L}$ amplification reaction. The reaction mix contained 0.4 units Taq DNA polymerase (Eurobio, Les Ulis, France), $1 \times$ polymerase buffer $(10 \times), 1.9 \mathrm{~mm}$ $\mathrm{MgCl}_{2}, 100 \mu \mathrm{M} \mathrm{dNTPs}$, and $0.2 \mu \mathrm{M}$ single decamer primer obtained from Operon Technologies Inc. (Alameda, CA, USA). Amplification was performed in a DNA thermal cycler (Perkin Elmer Cetus, Norwalk, USA) programmed for an initial denaturation cycle $\left(94^{\circ} \mathrm{C}\right.$ for $\left.30 \mathrm{~s}\right)$ followed by 45 cycles of $30 \mathrm{~s}$ at $92^{\circ} \mathrm{C}$, $1 \mathrm{~min}$ at $35^{\circ} \mathrm{C}$, and $2 \mathrm{~min} 30 \mathrm{~s}$ at $72^{\circ} \mathrm{C}$, with a final extension at $72^{\circ} \mathrm{C}$ for $5 \mathrm{~min}$. RAPD products were separated on a $1.8 \%$ agarose gel. Gels were stained with ethidium bromide and viewed with ultraviolet light. Lambda DNA restricted with HindIII and EcoRI was included as a molecular weight marker.

Amplifications were also performed with sequencegenerated primers (SG) specific to $P$. brassicae, developed by Buhariwalla et al. (1995). Sequence-generated primers were synthesized by ISOPRIM (Toulouse, France); primer sequence, reaction mix and amplification conditions were as indicated by Buhariwalla et al. (1995).

At least two replicates of the amplification assay were run with different template DNA obtained from different DNA extractions, to ensure the consistency of each DNA band. All amplifications were also performed with DNA from host Chinese cabbage cv. Granaat.

\section{Data analysis}

Only highly amplified reproducible bands of $P$. brassicae, clearly distinct from the host bands in

Table 2 Pathotype designation of the Plasmodiophora brassicae isolates in the Brassica napus differential set ${ }^{a}$

\begin{tabular}{llll}
\hline \multicolumn{5}{c}{ Differential host $B$. napus } \\
\cline { 2 - 4 } Pathotype & ECD 6 & ECD 10 & \\
& cv. Nevin & cv. Wilhelmsburger & cv. Brutor \\
P1 & + & + & + \\
P2 & + & - & + \\
P3 & - & - & + \\
P4 & - & - & - \\
P5 & - & + & + \\
P6 & + & - & - \\
P7 & + & + & - \\
P8 & + & + & \\
\hline &
\end{tabular}


the amplifications patterns, were scored and used for phenetic analysis. Data matrices were generated for the molecular data by scoring the absence of a DNA fragment as 0 and the presence of a band as 1 . Genetic distances were calculated with the following formula based on Jaccard's coefficient: $D=1-(1,1) /$ $[(1,1)+(0,1)+(1,0)]$, where $(1,1)$ is the number of bands shared by two patterns and $(0,1)+(1,0)$ the number of bands specific to one of the patterns. Mean genetic dissimilarities were calculated among field isolates, among SSIs derived from a single field isolate, and among SSIs according to pathotype, host and geographical origin. Dendrograms were constructed from the distance matrices with the UPGMA option of the program NEIGHBOR of PHYLIP $(3 \cdot 5 \mathrm{c}$ ) (Felsenstein, 1993). To determine the robustness of the dendrogram branches, 100 bootstrap replications were generated from the data using the program SEQBOOT; the resulting set of trees was synthesized using CONSENSE. Dendrograms were drawn with TREEviEw (Page, 1996).

\section{Results}

\section{Pathogenicity tests}

All the isolates were virulent and highly aggressive on the susceptible control Chinese cabbage cv. Granaat (disease index $>90 \%$, results not shown). The eight possible pathotypes were identified from the 46 isolates (Table 1). Pathotypes P7 (virulent on ECD10 host) and P1 (virulent on all three hosts) were the most common, comprising, respectively, 36 and $23 \%$ of the total sample. Among the nine field isolates, four different pathotypes (P1, P2, P5 and P7) were found. Among the 36 SSIs, seven pathotypes were identified (all except $\mathrm{P} 2$ ). All five SSIs derived from the $\mathrm{PbM}$ field isolate showed the same virulence pattern as the original field isolate (P1). In contrast, none of the nine SSIs derived from K92 expressed the same virulence pattern as the original field isolate (P2). Among the 23 SSIs derived from the field isolates SJ92 and Pb137, five different

Table 3 Primers used for the molecular characterization of Plasmodiophora brassicae, number of polymorphic bands analysed and bands specific to one isolate or to isolates belonging to one pathotype

\begin{tabular}{|c|c|c|c|c|c|}
\hline \multirow[b]{2}{*}{ Primer } & & & \multirow{2}{*}{$\begin{array}{l}\text { Number } \\
\text { of bands analysed }\end{array}$} & \multicolumn{2}{|c|}{ Specific bands } \\
\hline & & & & Marker & Isolate \\
\hline Operon & $\mathrm{A} 04$ & AATCGGGCTG & 1 & & \\
\hline \multirow[t]{19}{*}{$(\mathrm{OP})$} & $\mathrm{A} 07$ & GAAACGGTG & 6 & & \\
\hline & A10 & GTGATCGCAG & 1 & & \\
\hline & A13 & CAGCACCCAC & 5 & A13-400 & $\begin{array}{l}\text { All isolates belonging to } \\
\text { pathotype P1 }\end{array}$ \\
\hline & $\mathrm{J} 20$ & AAGCGGCCTC & 9 & & \\
\hline & K10 & GTGCAACGTG & 5 & & \\
\hline & K20 & GTGTCGCGAG & 5 & & \\
\hline & L02 & TGGGCGTCAA & 4 & & \\
\hline & L05 & ACGCAGGCAC & 2 & & \\
\hline & L10 & TGGGAGATGG & 4 & & \\
\hline & L12 & GGGCGGTACT & 6 & & \\
\hline & L14 & GTGACAGGCT & 4 & L14-1250 & K95 \\
\hline & & & & L14-1200 & $\begin{array}{l}\text { All isolates belonging to } \\
\text { pathotype P1 }\end{array}$ \\
\hline & L18 & ACCACCCACC & 4 & & \\
\hline & M05 & GGGAACGTGT & 3 & & \\
\hline & M14 & AGGGTCGTTC & 8 & & \\
\hline & N06 & GAGACGCACA & 2 & & \\
\hline & R02 & CACAGCTGCC & 2 & & \\
\hline & $\mathrm{R} 12$ & ACAGGTGCGT & 2 & & \\
\hline & $\mathrm{R} 15$ & GGACAACGAG & 6 & & \\
\hline \multirow[t]{9}{*}{$S^{a}$} & HKB 17/9 & CGTGGTTCCAATG & 4 & & \\
\hline & HKB 17/33 & GCATCGTCTG & 1 & & \\
\hline & HKB 23/52 & CGTGCGTACTTAGG & 6 & & \\
\hline & RFM3 & AAAGTGCCGGTTACCAGCAA & 2 & & \\
\hline & RFM4 & GATATCGAATTCGGTGCCCT & 2 & & \\
\hline & RFM7 & AAAGTGCCGGTTACCAGCAACTGA & 5 & RFM7-907 & SJ92-225 \\
\hline & RFM8 & GGAACAAGCTCGAAGCCATG & 1 & & \\
\hline & RFM9 & AGGTGAGGAGAAATGTCTC & 2 & & \\
\hline & RFM10 & CACGTACCGAACCTAACGAG & 1 & & \\
\hline
\end{tabular}

${ }^{a}$ SG, specific $P$. brassicae primers developed by Buhariwalla et al. (1995). 
pathotypes were found (P1, P4, P5, P7 and P8), with only two isolates expressing the same virulence pattern as the original field isolates (P5).

Different virulence patterns were found for some of the field isolates sampled from the same field and on the same host (K93, K94, K95 and K96 sampled at the same site (Kerdevez, Finistère) from Chinese cabbage, and SJ92 and SJ93 sampled at the same site (Saint

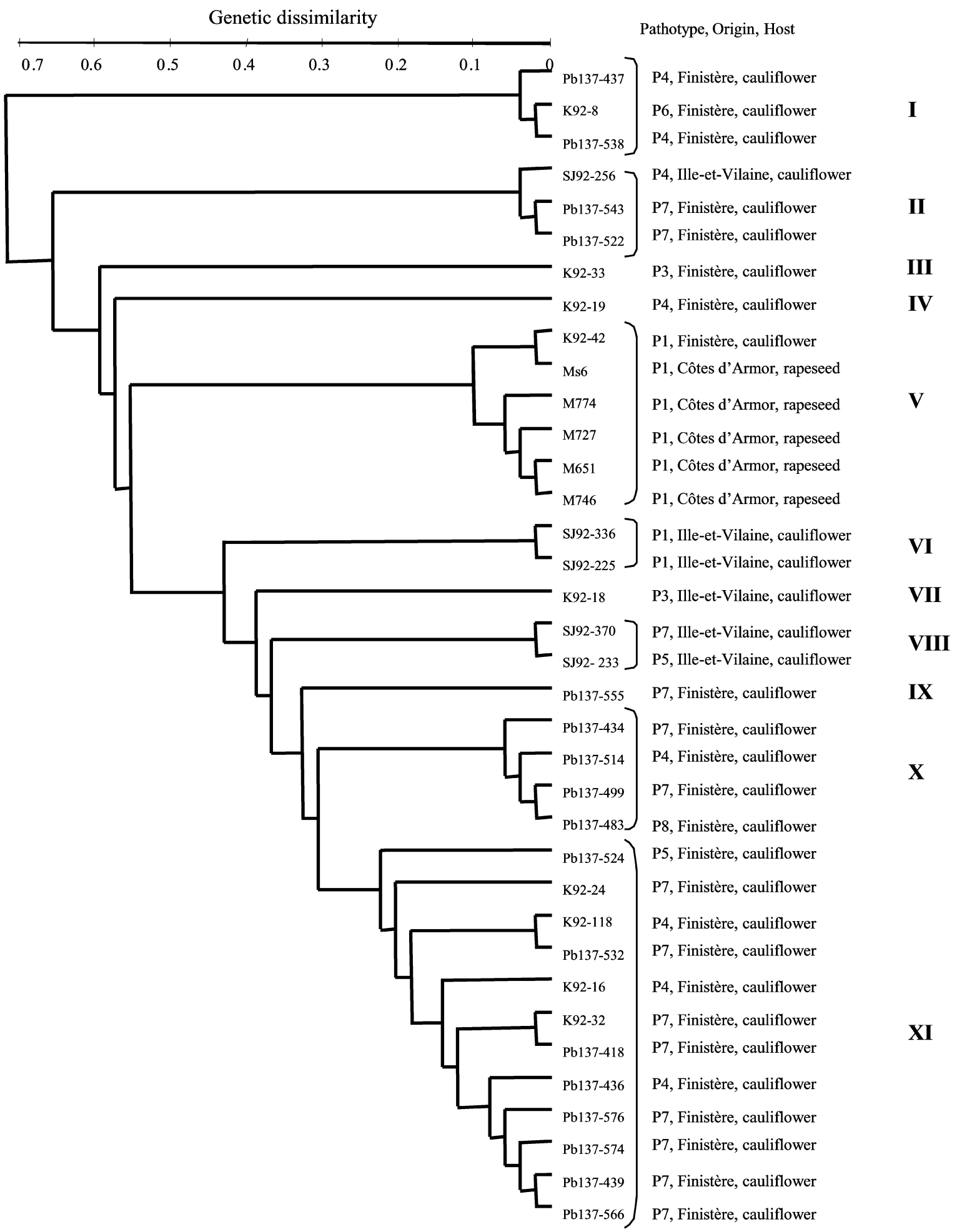

Fig. 1 Dendrogram of 37 single-spore isolates of Plasmodiophora brassicae based on 103 random amplified polymorphic DNA (RAPD and SG) loci, using the unweighted pair group arithmetic mean (UPGMA) program of PHYLIP (3.5c). 
Table 4 Genetic distances among groups of single-spore isolates of Plasmodiophora brassicae using RAPD and SG data according to the field isolate from which SSIs were derived, pathotype, host and geographical origin

\begin{tabular}{|c|c|c|c|}
\hline $\begin{array}{l}\text { Level } \\
\text { of comparison }\end{array}$ & Sublevel & $\begin{array}{l}\text { Number } \\
\text { of isolates }\end{array}$ & $\begin{array}{l}\text { Genetic } \\
\text { dissimilarity }^{\mathrm{a}}\end{array}$ \\
\hline \multirow[t]{4}{*}{ Field isolate } & $\mathrm{PbM}$ & 5 & $0 \cdot 273$ \\
\hline & K92 & 9 & 0.368 \\
\hline & SJ92 & 5 & 0.384 \\
\hline & $\mathrm{Pb} 137$ & 17 & $0 \cdot 341$ \\
\hline \multirow[t]{7}{*}{ Pathotype } & P1 & 8 & 0.326 \\
\hline & P3 & 2 & 0.474 \\
\hline & P4 & 8 & 0.434 \\
\hline & P5 & 2 & 0.323 \\
\hline & P6 & 1 & - \\
\hline & P7 & 14 & $0 \cdot 290$ \\
\hline & P8 & 1 & - \\
\hline \multirow[t]{2}{*}{ Host } & Cauliflower & 31 & $0 \cdot 366$ \\
\hline & Rapeseed & 5 & 0.273 \\
\hline \multirow[t]{3}{*}{ Geographic origin } & Côtes d'Armor & 5 & $0 \cdot 273$ \\
\hline & Finistère & 26 & 0.352 \\
\hline & Ille-et-Vilaine & 5 & 0.384 \\
\hline
\end{tabular}

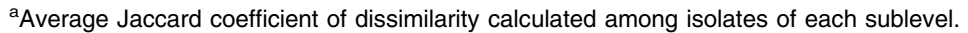

Jouan, Ille-et-Vilaine) from cauliflower but collected in different years. Of the four field isolates obtained from infected cauliflower, three pathotypes were identified. There was no obvious pattern linking virulence with host genotype or geographical origin.

\section{Molecular characterization}

Thirty-seven random primers and 10 SG primers were initially tested on a set of 16 isolates. All the amplifications were also performed on DNA from Chinese cabbage cv. Granaat. From this initial screening, primers were selected on the basis of (i) reproducible and polymorphic patterns yielded, and (ii) clear distinction between host and pathogen amplification products. Nineteen Operon primers and nine SG primers that consistently generated distinct reproducible polymorphic amplicons were retained for the molecular analysis (Table 3). A total of 103 polymorphic intense reproducible bands were amplified using the DNA from 45 isolates as templates. The size of the DNA fragments ranged from $0 \cdot 2$ to $2 \cdot 1 \mathrm{~kb}$. All RAPD profiles were fully reproducible in at least two independent assays using two independent DNA extractions.

Each SSI and field isolate had a unique multilocus molecular genotype. When the fingerprints of the 45 isolates were compared, only four bands were identified as pathotype- or isolate-specific (Table 3). Two primers (OPL14 and OPA13) gave profiles that matched the pathotype P1 classification based on the differential host set used. Isolate-specific markers were found for two isolates (K95 and SJ92-225).

The mean genetic dissimilarity obtained for the 45 isolates was $0 \cdot 375(\mathrm{CV}=15 \cdot 53 \%)$. The mean genetic distance among field isolates $(0 \cdot 346)$ was similar to the mean genetic distance within field isolates $(0 \cdot 341)$, except for isolate $\mathrm{PbM}$ from rapeseed in Côtes d'Armor, for which the variability within was lower than among field isolates (Table 4). Genetic distances were also calculated among SSIs grouped according to pathotype, host and geographical origin (Table 4). Whatever the grouping, a high level of genetic diversity was present among SSIs.

In the dendrogram constructed, 11 groups (I-XI) not consistently clustered (low bootstrap values) were observed (Fig. 1). These clusters could not be related to pathotype, host or geographic origin.

\section{Discussion}

The results of this study indicate that the populations of $P$. brassicae in Brittany are highly heterogeneous for both virulence and DNA pattern. Among the field isolates analysed, four different pathotypes were found. Among the 37 SSIs, seven pathotypes were found. The eight possible pathotypes that can be identified with the differential set used were detected in the restricted sample. Among these pathotypes, one (P8) had not been reported previously. The identification of the new pathotype was achieved with SSIs. These results confirm the high degree of variation for virulence found previously amongst French $P$. brassicae collections (Somé et al., 1996), and found by others around the world (Crute et al., 1980; Linnasalmi \& Toiviainen, 1991; Voorrips, 1995; Kuginuki et al., 1999). As pathotype identification depends on host genotype, isolates identified as a determined pathotype can be separated into more than one pathotype when more differential cultivars are used. Therefore natural 
P. brassicae variation for virulence is probably much greater than the variation reported here. The molecular markers distinguished many more genotypes than did differential hosts, each isolate having a unique molecular genotype. The RAPD and SG primers were selected to obtain as many polymorphic amplicons specific to one isolate or group of isolates as possible. It is obvious that selection of polymorphic bands leads, in contrast to the virulence study, to an overestimation of genetic dissimilarities between $P$. brassicae isolates; such amplicons would be of interest for the development of molecular epidemiological tools. Amplification of $P$. brassicae with arbitrary primers has proved to be successful for characterizing genetic diversity, as already established by Möller \& Harling (1996). Accurate choice of Operon primers and standardized conditions of $P$. brassicae DNA extraction produced simple amplification patterns that could be clearly interpreted, and with selected bands different from the host plant patterns, as with the SG primers (Buhariwalla et al., 1995).

Virulence and DNA polymorphisms were detected within and between field isolates, and among SSIs from different pathotypes, hosts and geographic origins. General mean genetic dissimilarity among 46 isolates of $P$. brassicae was high compared with genetic dissimilarity found in other obligate biotrophic fungi (Délye et al., 1997; Jennings et al., 1997), and in pathogens for which no sexual stage has been observed under field conditions (González et al., 1998; Hsiang \& Mahuku, 1999); comparable levels of genetic dissimilarity were observed among populations of the facultative stem canker pathogen Leptosphaeria maculans (Mahuku et al., 1997). The relatively high level of genetic diversity was similar among and within field isolates, i.e. genetic distances among SSIs derived from a single-club field isolate were similar to genetic distances among field isolates from different host and geographical origins. The life history of $P$. brassicae is not entirely understood, and there are uncertainties about some aspects of its population biology. There is still doubt concerning the relative roles of asexual propagation (secondary zoospores reinfecting root hairs) (Buczacki, 1983; Naiki et al., 1984; Mithen \& Magrath, 1992) and sexual propagation in the P. brassicae cycle, and where and how meiotic recombination takes place (fusion of secondary zoospores, Ingram \& Tommerup, 1972; myxamoebae fusion, Mithen \& Magrath, 1992). The degree of global variability (virulence and DNA patterns) assessed in the populations of $P$. brassicae studied, and the high level of genetic diversity observed at a very small scale (among SSIs from a single-club field isolate), support the assumption that recombination plays an important role in the cycle of the pathogen.

If variability for virulence is distributed at a very fine scale (a club), as indicated by the results presented here, the field isolates in this study were very complex composite populations (a mix of genotypes), supporting earlier reports (Jones et al., 1982b; Toxopeus et al., 1986). Moreover, among the SSIs derived from a singleclub field isolate, genotypes were detected that possessed more and less virulence than the original field isolate, and some genotypes (pathotype P2) could not be obtained as an SSI. These findings suggest that some kind of inhibition during pathotyping of the field isolates and selection for specific pathotypes during the SSI extraction process must be taking place. Similar results were obtained by Jones et al. (1982a) and Voorrips (1996), who explained this either by mechanisms of competition between pathogenic and nonpathogenic genotypes for infection sites, or by systems of resistance induced by nonpathogenic genotypes. These results underline the importance of using single-spore isolates instead of field isolates for both genetic studies of resistance and virulence surveys of the pathogen. For example, if virulent genotypes are masked (inhibited) by avirulent ones in a club, a plant could be selected as resistant to only the major component of the heterogeneous pathogen isolate (Somé et al., 1996; Voorrips, 1996). Bulking isolates would therefore mask much of the variability present and result in an artificially homogeneous population. However, single-spore isolation is not feasible in the routine identification of the virulence patterns of a large number of $P$. brassicae collections because of the time required and the variable success rate (Haji Tinggal \& Webster, 1981; Jones et al., 1982a; Scott, 1985; Manzanares et al., 1994; Narisawa et al., 1996; Voorrips, 1996).

Progress in identifying and monitoring variability in P. brassicae is possible by use of molecular markers that are isolate-specific or pathotype-specific. Results reported here, however, indicated that there was no clear relationship between the molecular analysis and the pathogenicity tests. Overall, the heterogeneous group of isolates could not be classified according to pathotype, host or geographical origin. The lack of correlation between virulence and/or DNA patterns and host origin (B. oleracea, B. rapa or B. napus) confirmed earlier studies showing no evidence for a pathogenic specialization of $P$. brassicae to a particular host species (Crute et al., 1983). The low correlation between virulence and RAPD patterns may be due to the high degree of DNA polymorphism among isolates within pathotypes. The evolution of the pathotype seems to be independent of the evolution of neutral DNA markers, as shown for other pathogens (Chen et al., 1993). Isolates classified here as pathotype P1 (virulent on all hosts) were clustered, although at low levels of similarity. Furthermore, two primers (OPL14 and OPA13) gave polymorphic patterns that matched the biological classification. A SCAR-PCR marker from the OPL14-1200 RAPD fragment differentiating the RAPD pattern of the isolates belonging to pathotype P1 has recently been developed (Manzanares-Dauleux et al., 2000), and further work is in progress to identify specific markers of other pathotypes. 
In conclusion, the finding that extensive genetic differences occur in $P$. brassicae populations should be an important consideration in choosing breeding tactics to develop durable clubroot resistance. Molecular markers that are genotype-specific can be useful for studying how hosts, cultural practices and environment affect the genetic structure of $P$. brassicae populations.

\section{Acknowledgements}

The authors are grateful to Drs D. Andrivon, H. Brun, A.M. Chèvre and E. Jenczewski for helpful discussions and critical review of the manuscript. The authors thank P. Glory and I. Brunot for technical assistance.

\section{References}

Buczacki ST, 1983. Plasmodiophora: an inter-relationship between biological and practical problems. In: Buczacki ST, ed. Zoosporic Plant Pathogens - A Modern Perspective. London, UK: Academic Press, 161-91.

Buczacki ST, Toxopeus H, Mattusch P, Johnston TD, Dixon GR, Hobolth LA, 1975. Study of physiological specialization in Plasmodiophora brassicae: proposals for attempted rationalization through an international approach. Transactions of the British Mycological Society 65, 295-303.

Buhariwalla H, Greaves S, Magrath R, Mithen R, 1995. Development of specific primers for the amplification of polymorphic DNA from the obligate root pathogen Plasmodiophora brassicae. Physiological and Molecular Plant Pathology 47, 83-94.

Chen X, Line RF, Leung H, 1993. Relations between virulence variation and DNA polymorphism in Puccinia striiformis. Phytopathology 83, 1489-97.

Crute IR, Gray AR, Crisp P, Buczacki ST, 1980. Variation in Plasmodiophora brassicae and resistance to clubroot disease in brassicas and allied crops - a critical review. Plant Breeding Abstracts 50, 91-104.

Crute IR, Phelps K, Barnes A, Buczacki ST, Crisp P, 1983. The relationship between genotypes of three Brassica species and collections of Plasmodiophora brassicae. Plant Pathology 32, 405-20.

Délye C, Laigret F, Corio-Costet MF, 1997. RAPD analysis provides insight into the biology and epidemiology of Uncinula necator. Phytopathology 87, 670-7.

Doyle JJ, Doyle JL, 1990. Isolation of plant DNA from fresh tissue. Focus 12, 13-5.

Felsenstein J, 1993. PHYLIP (PHYLogenetic Inference Package), Version $3.5 \mathrm{c}$ (distributed by the author). Seattle, Washington, USA: Department of Genetics, University of Washington.

González M, Rodríguez R, Zavala ME, Jacobo JL, Hernández F, Acosta J, Martínez O, Simpsom J, 1998. Characterization of Mexican isolates of Colletotrichum lindemuthianum by using differential cultivars and molecular markers. Phytopathology 88, 292-9.

Haji Tinggal SH, Webster J, 1981. Technique for single spore infection by Plasmodiophora brassicae. Transactions of the British Mycological Society 76, 187-90.

Hsiang T, Mahuku GS, 1999. Genetic variation within and between southern Ontario populations of Sclerotinia homoeocarpa. Plant Pathology 48, 83-94.

Ingram DS, Tommerup IC, 1972. The life history of Plasmodiophora brassicae Woron. Proceedings of the Royal Society, London B 180, 103-12.

Jennings JM, Newton AC, Buck KW, 1997. Detection of polymorphism in Puccinia hordei using RFLP and RAPD markers, differential cultivars, and analysis of the intergenic spacer region of rDNA. Journal of Phytopathology 145, 511-9.

Jones DR, Ingram DS, Dixon GR, 1982a. Characterization of isolates derived from single resting spores of Plasmodiophora brassicae and studies of their interaction. Plant Pathology 31, 239-46.

Jones DR, Ingram DS, Dixon GR, 1982b. Factors affecting tests for differential pathogenicity in populations of Plasmodiophora brassicae. Plant Pathology 31, 229-38.

Koch E, Cox R, Williams PH, 1991. Infection of Arabidopsis thaliana by Plasmodiophora brassicae. Journal of Phytopathology 132, 99-104.

Kuginuki Y, Yoshikawa H, Hirai M, 1999. Variation in virulence of Plasmodiophora brassicae in Japan tested with clubroot-resistant cultivars of Chinese cabbage (Brassica rapa L. spp. pekinensis). European Journal of Plant Pathology 105, 327-32.

Linnasalmi A, Toiviainen A, 1991. Occurrence of clubroot and Plasmodiophora brassicae Wor. races in Finland. Journal of Agricultural Science in Finland 63, 415-34.

Mahuku GS, Goodwin PH, Hall R, Hsiang T, 1997. Variability in the highly virulent type of Leptosphaeria maculans within and between oilseed rape fields. Canadian Journal of Botany $75,1485-92$.

Manzanares MJ, Laurens F, Baron F, Thomas G, 1994. Production of single spore isolates of Plasmodiophora brassicae. Cruciferae Newsletter 16, 131-2.

Manzanares-Dauleux MJ, Barret P, Thomas G, 2000. Development of a pathotype specific SCAR marker in Plasmodiophora brassicae. European Journal of Plant Pathology 106, 781-7.

Mithen R, Magrath R, 1992. A contribution to the life history of Plasmodiophora brassicae: secondary plasmodia development in root galls of Arabidopsis thaliana. Mycological Research 96, 877-85.

Möller M, Harling R, 1996. Randomly amplified polymorphic DNA (RAPD) profiling of Plasmodiophora brassicae. Letters in Applied Microbiology 22, 70-5.

Naiki T, Kawaguchi C, Ikegami H, 1984. Root hair reinfection in Chinese cabbage seedlings by the secondary zoospores of Plasmodiophora brassicae Woronin. Annals of the Phytopathological Society of Japan 50, 216-20.

Narisawa K, Kageyama K, Hashiba T, 1996. Efficient root infection with single resting spores of Plasmodiophora brassicae. Mycological Research 100, 855-8.

Page RDM, 1996. TREEVIEW: an application to display phylogenetic trees on personal computers. Computer Applications in the Biosciences 12, 357-8.

Schoeller M, Grunewaldt J, 1986. Production and characterization 
of single spore derived lines of $P$. brassicae Woron. Cruciferae Newsletter 11, 110-1.

Scott ES, 1985. Production and characterization of single-spore isolates of Plasmodiophora brassicae. Plant Pathology 34, 287-92.

Somé A, Manzanares MJ, Laurens F, Baron F, Thomas G, Rouxel F, 1996. Variation for virulence on Brassica napus $\mathrm{L}$. among Plasmodiophora brassicae collections from France and derived single-spore isolates. Plant Pathology 45, 432-9.

Toxopeus H, Dixon GR, Mattusch P, 1986. Physiological specialization in Plasmodiophora brassicae: an analysis by international experimentation. Transactions of the British Mycological Society 87, 279-87.

Voorrips RE, 1995. Plasmodiophora brassicae: aspects of pathogenesis and resistance in Brassica oleracea. Euphytica 83, 139-46.

Voorrips RE, 1996. Production, characterization and interaction of single-spore isolates of Plasmodiophora brassicae. European Journal of Plant Pathology 102, 377-83.

Williams PH, 1966. A system for the determination of races of Plasmodiophora brassicae that infect cabbage and rutabaga. Phytopathology 56, 624-6. 